\title{
Salivary gland carcinoma (SGC) with perineural spread and/or positive resection margin - high locoregional control rates after photon (chemo) radiotherapy - experience from a monocentric analysis
}

Marlen Haderlein ${ }^{1 *}$ D, Claudia Scherl ${ }^{2,4}$, Sabine Semrau ${ }^{1}$, Sebastian Lettmaier ${ }^{1}$, Markus Hecht ${ }^{1}$, Florian Putz ${ }^{1}$, Heinrich Iro' ${ }^{2}$ Abbas Agaimy ${ }^{3}$ and Rainer Fietkau ${ }^{1}$

\begin{abstract}
Background: The aim was to evaluate the outcome, especially locoregional control of patients with locally advanced salivary gland carcinoma (SGC) with perineural spread ( $\mathrm{Pn} 1$ ) and/or positive resection margins (R1/2) after postoperative photon (chemo) radiotherapy in a single centre.

Methods: We retrospectively reviewed data of 65 patients with newly diagnosed locally advanced SGC without distant metastases who underwent radio (chemo) therapy in the department of radiation oncology of the university hospital of Erlangen from January 2000 until April 2017.

Kaplan Meier method was used to calculate survival and recurrence rates. In univariate analysis the log-rank test was used to correlate patient-/tumor- and treatment-related parameters to survival and recurrence rates.
\end{abstract}

Results: Median follow-up was 45 months (range: 6; 215).

After 1, 3, 5 years cumulative incidence of local and locoregional failure was $3.1,7.0,7.0 \%$ and 3.1, 9.7, 12.9\%, whereas cumulative incidence of distant metastases (DM) was 15.6, 36.0, 44.0\%. After 1,3, 5 years cumulative Overall (OS) and Disease-free survival (DFS) was 90.5, 74.9, 63.9\% and 83.0, 54.8, 49.4\%.

The only significant predictor for decreased local and locoregional control was a macroscopic resection margin(R2) $(p=0$. 002 and $p=0.04)$. High-grade histology $(p=0.006)$, lymph node metastases with extracapsular spread $(p=0.044)$ and an advanced T-stage $(p=0.031)$ were associated with an increased rate of DM. High-grade histology was the only factor predicting for a decreased DFS $(p=0.014)$.

Conclusion: Photon radiotherapy leads to high local and locoregional control rates in a high-risk patient population with SGC with microscopically positive resection margins and/or perineural spread. The most common site of disease recurrence was distant metastases. Therefore the real challenge for the future should be to prevent distant metastases.

Keywords: Salivary gland cancer, Locoregional control, Perineural spread, Positive resection margin, Photon radiotherapy

\footnotetext{
* Correspondence: marlen.haderlein@uk-erlangen.de

'Department of Radiation Oncology, University Hospital,

Friedrich-Alexander-Universität Erlangen-Nürnberg (FAU), D-91054 Erlangen,

Germany

Full list of author information is available at the end of the article
}

(c) The Author(s). 2019 Open Access This article is distributed under the terms of the Creative Commons Attribution 4.0 International License (http://creativecommons.org/licenses/by/4.0/), which permits unrestricted use, distribution, and reproduction in any medium, provided you give appropriate credit to the original author(s) and the source, provide a link to the Creative Commons license, and indicate if changes were made. The Creative Commons Public Domain Dedication waiver (http://creativecommons.org/publicdomain/zero/1.0/) applies to the data made available in this article, unless otherwise stated. 


\section{Introduction}

Salivary gland carcinoma is a rare tumor entity including a variety of different histologic subgroups [1]. Large retrospective studies provide evidence suggesting a benefit of postoperative external beam radiotherapy in locally advanced salivary gland cancer [2, 3]. Especially in patients with perineural invasion and/or positive resection margins locoregional tumor control after surgery is low [2-4]. Moreover adenoidcystic carcinoma (ACC) is known as a radioresistant tumor and in case of macroscopic tumor high LET (linear energy transfer) radiation with protons or especially carbon ions might be beneficial [5-7]. In recent times high LET radiation was also investigated in patients with all kinds of salivary gland carcinomas in case of high-risk features (positive resection margin and/or perineural invasion) in the postoperative situation [8-10].

Of the large retrospective studies that support effectiveness of postoperative photon radiotherapy [11] in patients with locally advanced SGC there is no study that only investigates patients with the high-risk features perineural spread and/or positive resection margins like those patients who met inclusion citeria for participating in trials using carbon ion radiotherapy in the postoperative situation. The purpose of this retrospective monocentric analysis was to evaluate local/locoregional control (LC/LRC) in patients with salivary gland carcinoma with microscopic or grossly positive (R1/R2) resection margins and/or perineural invasion after postoperative radio (chemo) therapy with photons. Therefore we reviewed all patients with salivary gland carcinoma with positive resection margin and/or perineural spread, who underwent postoperative radio (chemo) therapy in our department between 2000 and 2017.

\section{Material and methods}

\section{Data collection, patient characteristics}

We reviewed clinical records of patients with newly diagnosed locally advanced salivary gland carcinoma of the head and neck region who were treated with surgery followed by radio (chemo) therapy from January 2000 until April 2017. Only patients with perineural invasion (Pn1) and/or positive resection margins ( $\mathrm{R} 1 / \mathrm{R} 2$ resection) were included in the analysis. Moreover patients with distant metastases at the date of first diagnosis, patients with squamous cell carcinoma or patients who underwent brachytherapy alone were excluded.

For detailed patient information see Table 1:

\section{Treatment}

All patients were treated with surgery followed by radiotherapy or radiochemotherapy with curative intention. Local resection of primary tumor was performed in all patients. A second primary tumor resection was necessary in 14 patients $(21.5 \%)$. Resection margin was negative in 40 patients $(61.5 \%)$ and microscopically positive in 19 patients and 6 patients had a macroscopically positive resection margin in the final pathologic results. 48 (73.8\%) patients underwent ipsilateral neck dissection alone, 7 patients (10.8\%) underwent bilateral neck dissection and in 10 (15.4\%) patients no neck dissection was performed. Forty-one patients (63.1\%) received chemotherapy simultaneously. Of these 41 patients 38 patients received platinum-based and 3 patients mitomycin c based chemotherapy. Usually chemotherapy was recommended for patients with locally advanced T-stage T3/4, high grade disease, lymph node metastases with perinodal spread, $\geq 3$ lymph node metastasis or positive/close resection margins. Patients with these tumor characteristics, who did not receive additional chemotherapy, either refused chemotherapy or suffered from comorbidities (1 patient), that did not allow chemotherapy .

The median radiotherapy dose administered was $64 \mathrm{~Gy}$ (range: 45Gy; 74.2Gy).

Target volume delineation was performed on a contrast-enhanced computed tomography scan. The preoperative CT and/or MRI scan was fused to the planning CT.

CTV always included the primary tumor region along the nerve tracts up to the base of skull. In case of positive ipsilateral neck nodes ipsilateral lymph nodes were included and if the primary tumor was located at or crossing the midline or patients had multiple ipsilateral lymph node metastases with extracapsular extension, bilateral nodes were included.

After treatment patients had regular follow-up visits in our department as well as in the department of otorhinolaryngology. Usually these visits occurred every 3 months in the first 2 years after treatment, then every 6 months and after 5 years patients had yearly follow-up visits. Usually patients underwent an ENT examination and an ultrasound of the neck at every visit. Every 6 months in the first 5 years patients received an x-ray or $\mathrm{CT}$ of the chest (CT usually including the upper stomach). In case of symptoms diagnostic imaging was performed immediately.

\section{Statistics/analysis of data}

Overall survival and disease-free-survival as well as the cumulative incidence of locoregional-recurrence and distant metastases were scored from the time of first diagnosis (defined as the date of biopsy or surgery of the primary tumor). Disease-free survival was defined as the absence of locoregional or distant disease recurrence and death from any cause. Statistical 
Table 1 Patient characteristics

\begin{tabular}{l} 
Patients' characteristics $(n=65)$ \\
\hline Characteristics \\
\hline Gender (Number of patients) \\
male \\
Age at diagnosis (years) \\
Median \\
Range \\
Primary tumor site (Number of pate \\
Parotid Gland \\
Submandibular Gland \\
Minor Salivary Glands: \\
- Nasal cavity/paranasal sinus \\
- Hard palate \\
- Tongue/base of tongue \\
- Meatus acusticus \\
- Floor of mouth \\
- Cheek
\end{tabular}

Histologic Subtypes (Number of patients)

Adenoidcystic Carcinoma
Mucoepidermoid Carcinoma
Ductal Adenocarcinoma
Adenocarcinoma NOS
Acinic cell carcinoma
other

Tumor stage (Number of Patients)

$\begin{array}{ll}\text { pT1 } & 9 \\ \text { pT2 } & 10 \\ \text { pT3 } & 3 \\ \text { pT4 } & 1 \\ \text { pT4a } & 13 \\ \text { pT4b } & 3 \\ \text { Primary tumor size }(\mathrm{cm}) & \end{array}$

Primary tumor size $(\mathrm{cm})$

Median:

Range:

Nodal Stage (Number of Patients)

c/pNO

pN1

pN2b

Perinodal Spread (Number of Patients)

no

yes

unknown

Lymphangiosis (Number of patients)

LO

$\begin{array}{ll}\text { Value } & \% \\ 30 & 46.2 \% \\ 35 & 53.8 \%\end{array}$

57

26-83

36

11

18

6

3

5

2

1

1

25

13

19

4

2

2

9

10

30

16

13

3

$55.4 \%$

$27.7 \%$

$38.5 \%$

$20.0 \%$

$29.2 \%$

$6.2 \%$

$15.4 \%$

$46.2 \%$

$24.6 \%$

$41.5 \%$

$21.5 \%$

$36.9 \%$

$60.0 \%$

$32.3 \%$

$7.7 \%$
Table 1 Patient characteristics (Continued)

Patients' characteristics $(n=65)$

\begin{tabular}{cll}
\hline Characteristics & Value & $\%$ \\
\hline L1 & 20 & $30.8 \%$ \\
Lx & 2 & $3.1 \%$
\end{tabular}

Hemangiosis (Number of patients)

$\begin{array}{lll}\text { V0 } & 52 & 80.0 \% \\ V 1 & 11 & 16.9 \% \\ V x & 2 & 3.1 \%\end{array}$

Perineural Spread (Number of Patients)

Pno

$9.2 \%$

Pn1

$90.8 \%$

Resection margin (Number of Patients)

RO

$61.5 \%$

R1

40

$29.2 \%$

R2

$9.2 \%$

Grade of Differentiation (Number of Patients)

Low-grade

$9.2 \%$

Intermediate-grade

$16.9 \%$

High-grade

$72.3 \%$

Gx

$1.5 \%$

Bone Infiltration of primary tumor

No

$90.8 \%$

Yes

$9.2 \%$

Neck Dissection (Number of Patients)

None

$15.4 \%$

Ipsilateral

$73.8 \%$

Bilateral

$10.8 \%$

Radio (chemo) therapy (Number of patients)

Radiation alone

$36.9 \%$

Radiochemotherapy

$63.1 \%$

Radiation dose (Gy):

Median: 64

Range: 45-74.2Gy

Radiation technique (Number of patients)

3D:

38

$58.5 \%$

IMRT:

$41.5 \%$

Planning target volume (number of patients)

Primary tumor region

$16.9 \%$

Primary tumor region, ipsilateral neck

$53.8 \%$

Primary tumor region, bilateral neck

$29.2 \%$

analysis was performed using the SPSS software version 21. The Kaplan-Meier-Method was used for calculating estimated overall-survival, disease-freesurvival and the cumulative incidence of local/locoregional control and distant metastases. In univariate 
analysis the log-rank-test was used to correlate patient- tumor- and treatment-related parameters with overall-survival, disease-free-survival, incidence of local/loregional recurrences and distant metastases. Therefore the following dichotome risk-classification of the different variables was used considering the limited number of patients: gender; age $(<70$ years, $\geq 70$ years); adenoidcystic vs. non-adenoidcystic carcinoma; tumor site (parotid vs non-parotid); T-stage(T1/ 2 vs T3/4); tumor $\operatorname{size}(\leq 3 \mathrm{~cm}$ vs $>3 \mathrm{~cm}$ ); $\mathrm{N}$-stage (N0 vs N1/2); number of metastatic lymph nodes: $>1$ vs. $\leq 1$; extranodal extension; perineural spread; lymphovascular/vascular invasion; high vs. low/intermediate grade; resection margin( $\mathrm{R} 0$ vs $\mathrm{R} 1 / 2 ; \mathrm{R} 0 / 1$ vs. R2); neck dissection; number of dissected lymph nodes $(\geq 10$ vs. $<10$;); Lymph node density ( $\leq 4$ vs $>4$ ), second primary tumor resection; applied radiation dose $(<64$ Gy vs $\geq 64$ Gy), radiation technique (3D vs. IMRT). Only variables yielding $p$-values of $\leq 0,05$ were subsequently included in the multivariate analysis. For multivariate analysis the cox regression analysis was used.

A two-sided $\mathrm{p}$-value $<0,05$ was considered to be statistically significant.

\section{Results}

Median follow-up was 45 months (range: 6; 215). Of the 65 patients perineural spread was present in 59 patients and positive resection margins in 25 patients, 19 patients showed perineural spread and a positive resection margin.

Of the 65 patients included in the analysis, seven (10.8\%) developed local relapse and 28 (43.1\%) developed distant metastases .

At the last follow-up, 29 patients (44.6\%) were still alive and free from recurrence.

\section{Local/Locoregional recurrence}

Cumulative incidence of local recurrence (see Fig. 1) and locoregional recurrence (see Fig. 2) was 3.1, 7.0, 7.0\% and $3.1,9.7,12.9 \%$ after 1,3 and 5 years.

The only parameter correlating significantly with the incidence of local (see Fig. 3a) recurrence was a macroscopic resection margin $(p=0.002)$. In univariate analysis gender $(p=0.05)$ and a macroscopic resection margin $(p=0.031)$ were significantly associated with decreased locoregional control. For detailed information see in the Appendix in Table 3. In multivariate analysis only a macroscopic resection margin remained a significant predictor $(p=0.04)$ (see Fig. $3 \mathrm{~b})$. Three of the 40 patients with R0 resection, 2 of the 19 patients with microscopic positive resection margin and 2 of the 6 patients with grossly positive resection margin developed a locoregional recurrence.

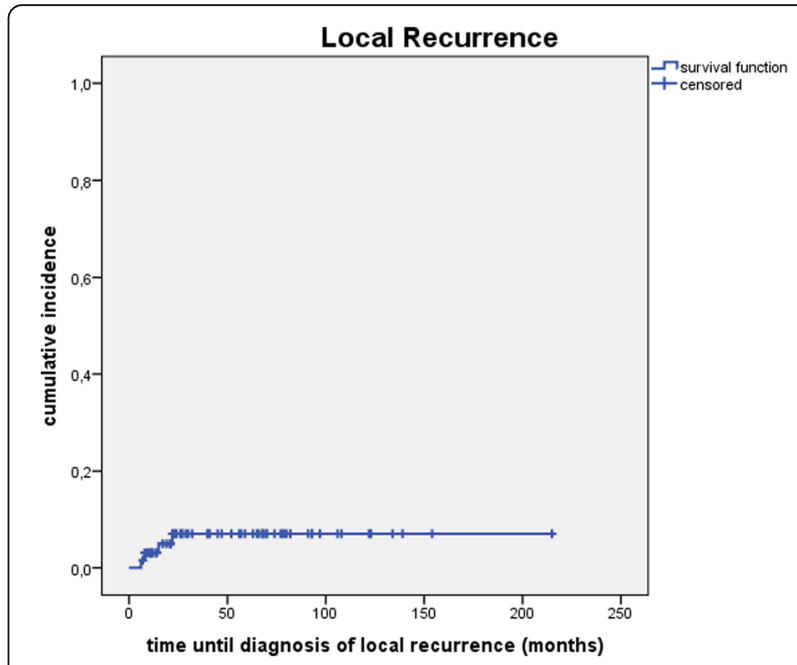

Fig. 1 Cumulative incidence of local recurrence

In this context it should be noted that one of the 2 grossly positive resected patients who developed a local recurrence had the R2 situation not in the primary tumor region but in the cervical lymph nodes.

There was a trend towards superior local control for intensity-modulated radiotherapy in comparison to 3D-conformal radiotherapy $(p=0.099)$.

Overall locoregional recurrences were diagnosed in 7 patients. Five of these patients also developed distant metastases, whereas in 2 patients synchronous distant metastases occurred, in one patient distant metastases were already known 18 months before occurrence of locoregional recurrence and in two patients distant metastases were diagnosed after diagnosis of locoregional recurrence. Four of these 7 recurrences were in-radiation-field recurrences while

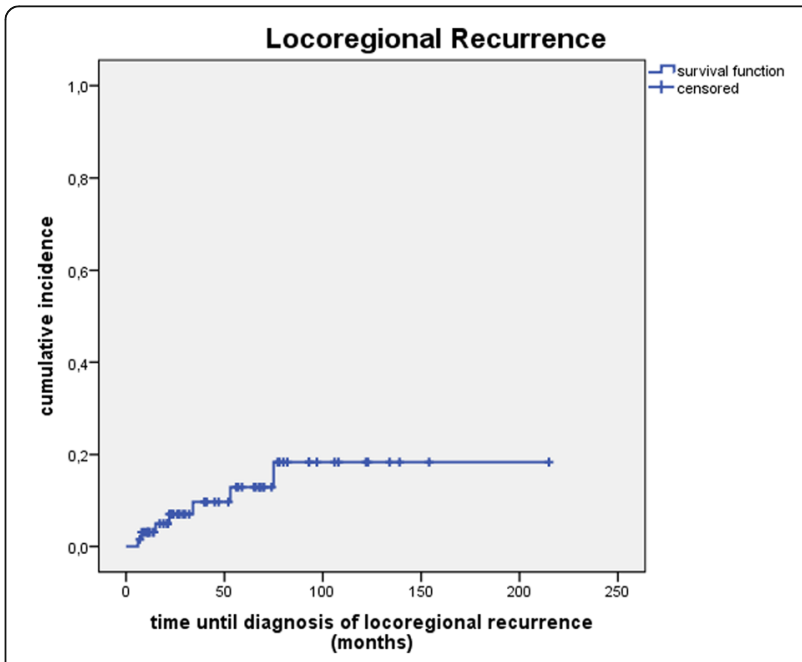

Fig. 2 Cumulative incidence of locoregional recurrence 

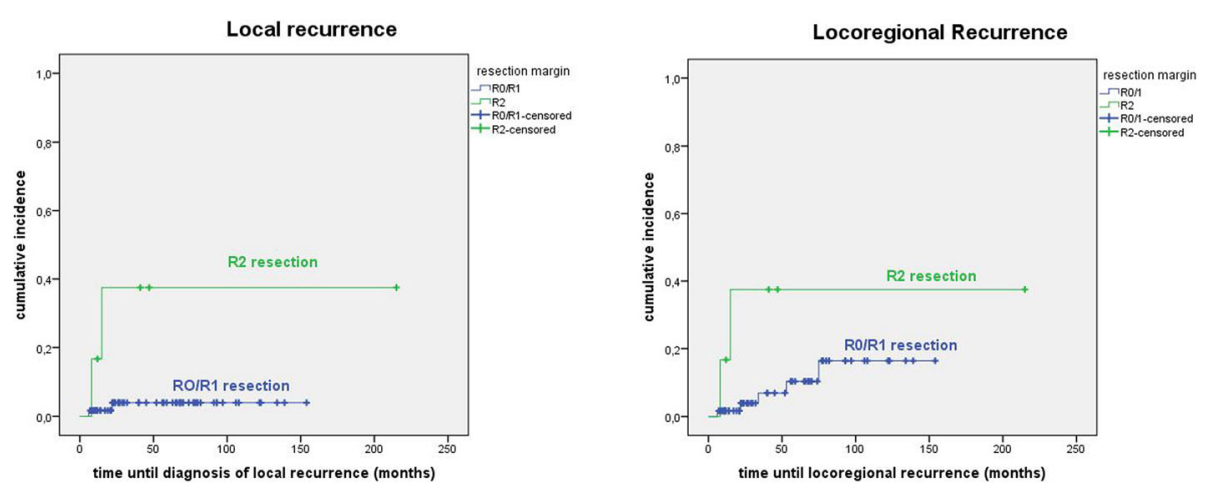

Fig. 3 Cumulative incidence of local (3a) and locoregional (3b) recurrence according to resection margin

the remaining 2 were outside the radiation field (one in the contralateral lymph nodes, one in the thyroid gland) and one in the margin of the radiation field: the sinus cavernosus (for detailed information see Table 2).

\section{Overall and disease-specific survival}

OS was $90.5,74.9$ and $63.9 \%$ after 1,3 and 5 years. Disease-specific survival was 93.6, 80.8 and $71.0 \%$ after 1,3 and 5 years.

\section{Disease-free survival}

DFS was 83.0, 54.8 and $49.4 \%$ after 1,3 and 5 years (see Fig. 4).
In univariate analysis high-grade histology ( $p=$ 0.014) was the only significant predictor for a decreased DFS. In patients with low-or intermediate grade salivary gland carcinoma DFS was 100, 82.4, $82.4 \%$ after 1,3 and 5 years while in patients with high-grade histology DFS was 76.4, 44.0, 35.8\% after 1,3 and 5 years.

\section{Distant metastases}

Cumulative incidence of distant metastases was 15.6, 36.0 and $44.0 \%$ after 1,3 and 5 years (see Fig. 5).

Distant metastases were found in the following locations: lung: $n=19$ patients, bone: $n=3$ patients, liver: $n$ $=2$ patients, disseminated: $n=4$ patients.

Table 2 Locoregional recurrences

\begin{tabular}{|c|c|c|c|}
\hline Patient & Tumor histology /stage & Localisation of locoregional recurrence & In-Field \\
\hline $\begin{array}{l}\text { Pat.1 } \\
\text { (male) }\end{array}$ & $\begin{array}{l}\text { High-grade mucoepidermoid carcinoma } \\
\text { of the parotid gland } \\
\text { pT3pN1(1/18)L1V1Pn1R0 }\end{array}$ & $\begin{array}{l}\text { Gingiva, Mandibula with infiltration of the skin, also disseminated } \\
\text { lung metastases at the timepoint of diagnosis of locoregional } \\
\text { recurrence }\end{array}$ & yes \\
\hline $\begin{array}{l}\text { Pat.2 } \\
\text { (male) }\end{array}$ & $\begin{array}{l}\text { Ductal adenocarcinoma of the parotid gland, } \\
\text { high-grade } \\
\text { pT4pN2b(19/38)L1VOPn1 } \\
\text { R2 (detection of supraclavicular lymph node } \\
\text { metastases before start of radiochemotherapy) }\end{array}$ & $\begin{array}{l}\text { Recurrence in the parotid region with orbital infiltration, also } \\
\text { disseminated bone metastases at the timepoint of diagnosis } \\
\text { of locoregional recurrence }\end{array}$ & yes \\
\hline $\begin{array}{l}\text { Pat.3 } \\
\text { (male) }\end{array}$ & $\begin{array}{l}\text { Intermediate-grade mucoepidermoid carcinoma } \\
\text { of the parotid gland } \\
\text { pT1pN2b(2/3)LOVOPnOR1 }\end{array}$ & $\begin{array}{l}\text { Recurrence in the parotid region (R0 resection of recurrence } \\
\text { was possible) }\end{array}$ & yes \\
\hline $\begin{array}{l}\text { Pat.4 } \\
\text { (male) }\end{array}$ & $\begin{array}{l}\text { Low-grade adenoidcystic carcinoma of the } \\
\text { submandibular gland } \\
\text { pT3pNO(0/34)LOVOPn1R1 }\end{array}$ & $\begin{array}{l}\text { Recurrence in the thyroid gland, diagnosis of lung metastases } \\
13 \text { months after diagnosis of locoregional recurrence }\end{array}$ & No \\
\hline $\begin{array}{l}\text { Pat.5 } \\
\text { (male) }\end{array}$ & $\begin{array}{l}\text { Ductal carcinoma of the parotid gland, high-grade } \\
\text { pT4pN2b(22/28)LxVxPn1RO }\end{array}$ & $\begin{array}{l}\text { Contralateral lymph node metastases, diagnosis of lung and liver } \\
\text { metastases } 6 \text { months after diagnosis of locoregional recurrence }\end{array}$ & no \\
\hline $\begin{array}{l}\text { Pat.6 } \\
\text { (female) }\end{array}$ & $\begin{array}{l}\text { High-grade adenoidcystic carcinoma of the sinus } \\
\text { maxillaris on the left side with skull base and orbital } \\
\text { infiltration } \\
\text { pT4cN1R2 }\end{array}$ & Recurrence in sinus maxillaris & yes \\
\hline $\begin{array}{l}\text { Pat.7 } \\
\text { (male) }\end{array}$ & $\begin{array}{l}\text { High grade adenoidcystic arcinoma of the } \\
\text { submandibular gland on the left side } \\
\text { pT3 pNO (0/24) CMO LO VO Pn1 RO }\end{array}$ & $\begin{array}{l}\text { Recurrence in Sinus cavernosus, also disseminated lung metastases } \\
\text { diagnosed } 18 \text { months before diagnosis of locoregional recurrence }\end{array}$ & $\begin{array}{l}\text { Margin of } \\
\text { radiation field }\end{array}$ \\
\hline
\end{tabular}




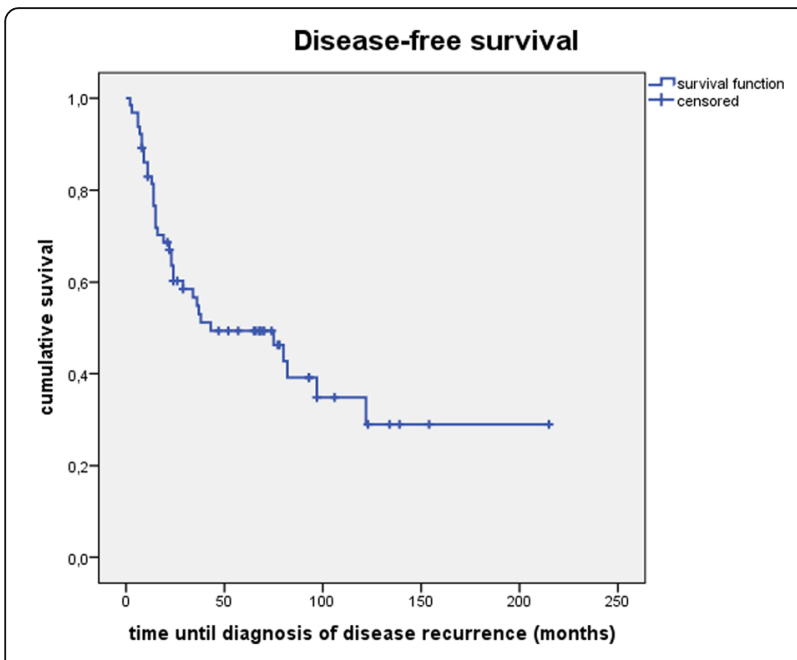

Fig. 4 Disease-free survival

In univariate analysis an advanced T-Stage $(p=$ $0.031)$, high-grade histology $(p=0.006)$ and the presence of extracapsular extension of lymph node metastases $(p=0.044)$ was associated with an increased incidence of distant metastases. In multivariate analysis none of the variables reached statistical significance.

\section{Discussion}

This study evaluates the outcome of patients with salivary gland carcinoma (SGC) with positive resection margin and/or perineural invasion after photon (chemo-)radiotherapy. Because of the rarity of SGC no prospective study on the impact of radiotherapy in

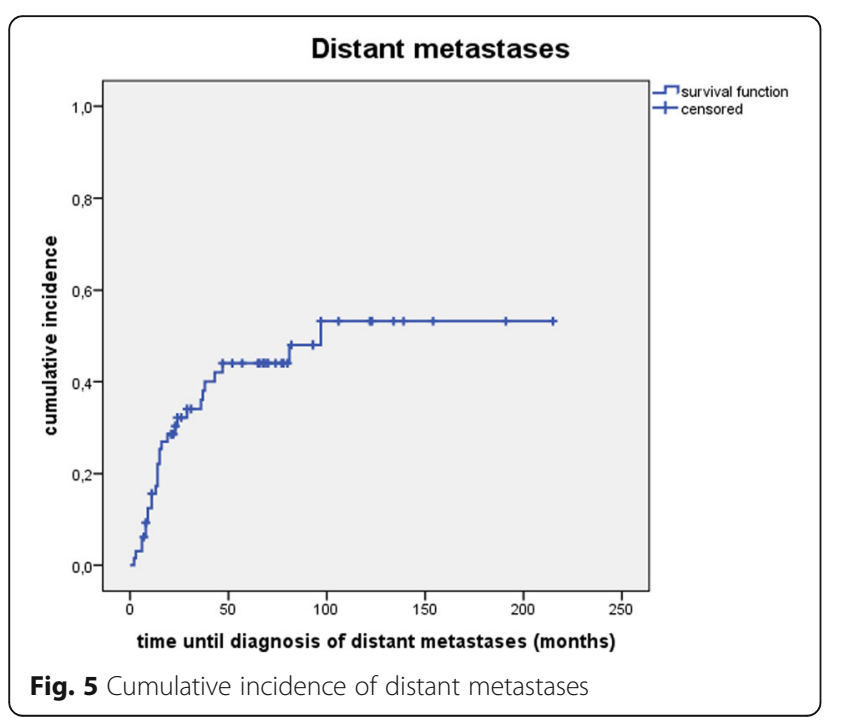

the postoperative situation is available. There is evidence from large retrospective studies and experience from single centre evaluations that show a benefit of postoperative radiotherapy in patients with SGC with high-risk features [2, 3]. In retrospective studies a positive resection margin and/ or perineural spread were identified as risk factors for locoregional recurrence of salivary gland cancer [2-4].

To the best of our knowledge this is the only retrospective analysis of the impact of photon (chemo) radiotherapy in patients with SGC after surgery, which only includes patients with positive resection margin and/or perineural spread.

This retrospective study shows high local and locoregional control rates of over 93 and $87.1 \%$ after 5 years in a high-risk population of patients with salivary gland carcinoma. In 7 out of 65 patients locoregional recurrence occurred.

The COSMIC trial [8-10] investigates the effect of carbon ion radiotherapy in all kinds of SGC including patients with microscopic resection margins defined as microscopically positive resection margin and/or showing perineural spread (referred to as R1-group). Preliminary results of the cosmic trial show a locoregional control rate of $89.7 \% / 86.9 \%$ and a PFS of $64.6 \% / 58.8 \%$ after 3 years in the R1/R2 group compared to a locoregional control rate of $87.1 \%$ and a DFS of $54.8 \%$ after 3 years in our retrospective analysis.

It has to be mentioned that some patient characteristics were different in the COSMIC trial in comparison to our study. First of all 14 of the 20 patients (70\%) in the group with microscopic positive resection margin and all patients of the group with macroscopic positive resection margin of the cosmic trial were patients with adenoidcystic carcinomas. The authors of the study state that "there were no significant differences between ACC and non-ACC histologic features regarding LC, PFS or OS." In our analysis $38.5 \%$ of patients had an adenoidcystic carcinoma, followed by patients with salivary duct carcinoma (29\%) and mucoepidermoid carcinoma (20\%). The high percentage of salivary duct carcinomas, which are known for their high rate of developing distant metastases [12-14] during follow-up, might explain the decreased disease-free survival in our study. Moreover in our patient population most patients had salivary gland cancer of the parotid gland (55\%) whereas in the cosmic trial most of the patients had their primary tumor located in a minor salivary gland (especially paranasal sinus and palate).

Nevertheless, our results show a high local and locoregional control rate in patients with salivary gland carcinoma independent of tumor type and 
tumor location. The only significant predictor for decreased local and locoregional control was a macroscopic resection margin. There were, however, only 6 patients with an R2 resection in our analysis. Two of these patients developed local recurrence, with one of these patients having the R2 situation not in the primary tumor region, where the recurrence occurred, but in the cervical lymph nodes. Moreover it is worth noting, that the locoregional control rate of our analysis is comparable to that of the R1 group of the COSMIC trial. In the R1 group of the COSMIC trial no patients with macroscopic tumor margin were included.

Despite the high locoregional control rate DFS was only $49.4 \%$ after 5 years, because of a high rate of distant failure (44\% after 5 years). Interestingly, in the Cosmic trial the first site of failure was also distant ( $>50 \%$ of the patients). Moreover other retrospective trials [15-17] report high rates of distant metastases in up to $47.3 \%$ of patients with salivary gland cancer, especially in high-grade carcinomas. Considering the high rates of locoregional control it is doubtful whether carbon ion radiotherapy is superior to photon radiotherapy in patients with salivary gland cancer with microscopically positive resection margins and/or perineural spread. In patients with macroscopic resection margin carbon ion radiotherapy might be considered.

Intensity-modulated radiotherapy showed a trend towards improved local control when compared to 3D-conformal radiation. None of the patients in the IMRT group developed a local recurrence, but follow-up is shorter in this group than in the $3 \mathrm{~d}$-conformal group.

The implementation of IMRT in recent years in combination with image-guided radiotherapy and their continuous development has led to the possibility of dose escalation in the tumor region while simultaneously reducing radiation dose at the organs at risk [18-25]. Especially in critical regions like the skull base highly conformal radiotherapy with IMRT might be beneficial $[26,27]$. This means that in our patient population local control might even have been higher, if all patients had been treated with IMRT. Patients that were treated with 3D-conformal radiotherapy are not comparable to patients treated with carbon ion radiotherapy.

In this analyses high-grade histology is the only significant predictor for a decreased DFS as also reported in a previous study [28]. Furthermore patients with high-grade histology, an advanced T-stage and the presence of extracapsular extension of lymph node metastases show a significant higher rate of distant metastases during follow-up. These findings are in line with the literature [4, 16, 28]. An advanced T-Stage is associated with a higher rate of distant metastases but not with a decreased local control. It may therefore be assumed that in patients with an advanced T-stage und additional risk factors like positive resection margin and/or perineural spread, the risk of development of distant metastases is much higher than that of experiencing locoregional recurrence.

Laramore et al. [29] in their final report on the RTOG trial comparing definitive neutron and photon radiotherapy stated, that local control was increased by neutron therapy, but that this did not translate into an improved overall survival, because of the high rate of distant metastases during follow-up.

In future the real challenge will therefore be to investigate intensified first-line systemic treatments to decrease the rate of distant metastases.

It also has to be mentioned, that this study has several limitations. First of all the evaluation we performed was retrospective with a small number of patients and with a heterogeneous mix of different tumor subtypes and sites, which makes the evaluation of treatment outcome more difficult. Moreover because of the retrospective nature of our study the times at which radiologic imaging was performed were not clearly defined and might have influenced the survival analysis. Radiation techniques have changed over the last few years. The implementation of intensity-modulated radiotherapy in combination with image-guided radiotherapy has led to higher treatment accuracy and to the possibility of applying higher doses to the tumor region. Therefore the fact that we included patients, who were irradiated using 3D-conformal techniques may have led to lower locoregional control rates in our study. It is doubtful if a multivariate analysis makes sense considering the small number of patient. Toxicity was not assessed. This could be a potential advantage ofproton or carbon ion radiotherapy over radiotherapy with photons.

Despite these shortcomings this retrospective study shows that in patients with salivary gland carcinoma high local and locoregional control rates are achieved even in patients with positive microscopic resection margins and/or perineural spread after postoperative radiotherapy with photons. In the future the real challenge in the treatment of salivary gland cancer will be the optimization of systemic treatment options to decrease distant failure.

\section{Conclusion}

Photon radiotherapy leads to high local and locoregional control rates in a high-risk patient population with SGC with microscopically positive resection margins and/or perineural spread. The most common site of disease recurrence was distant metastases. Therefore the real challenge for the future should be to prevent distant metastases. 


\section{Appendix}

Table 3 Patient-, tumor-and treatment-related factors compared to local and locoregional recurrences

\begin{tabular}{|c|c|c|}
\hline \multicolumn{3}{|l|}{ Univariate } \\
\hline & $\begin{array}{l}\text { Local recurrence } \\
\text { p-value } \\
\text { Hazard ratio } \\
\text { (95\% confidence interval) }\end{array}$ & $\begin{array}{l}\text { Locoregional recurrence } \\
\text { p-value } \\
\text { Hazard ratio } \\
\text { (95\% confidence interval) }\end{array}$ \\
\hline \multicolumn{3}{|l|}{ Patient-dependent } \\
\hline Gender & 0.389 & 0.050 \\
\hline female vs. male & $0.38(0.04-3.69)$ & $0.16(0.02-1.31)$ \\
\hline Age at diagnosis & 0.839 & 0.828 \\
\hline$\geq 70 y$ vs. $<70 y$ & $1.27(0.13-12.24)$ & $0.79(0.09-6.68)$ \\
\hline \multicolumn{3}{|l|}{ Tumor-related } \\
\hline Primary tumor site & 0.368 & 0.664 \\
\hline non-parotid vs. parotid & $0.37(0.04-3.54)$ & $0.72(0.16-3.23)$ \\
\hline Histologic Subtype & 0.541 & 0.953 \\
\hline non-adenoidcystic vs. & 2.00 & 0.956 \\
\hline adenoid cystic & $(0.21-19.21)$ & $(0.21-4.29)$ \\
\hline T classification & 0.773 & 0.196 \\
\hline T3/4 vs. T1/2 & $1.39(0.15-13.43)$ & $3.75(0.44-31.85)$ \\
\hline Primary tumor size, $\mathrm{cm}$ & 0.703 & 0.711 \\
\hline$>3 \mathrm{~cm}$ vs. $\leq 3 \mathrm{~cm}$ & $0.63(0.06-6.95)$ & $1.35(0.27-6.72)$ \\
\hline N classification & 0.075 & 0.227 \\
\hline N1/2 vs. NO & $53.2(0.02-180,704.08)$ & $2.68(0.51-14.09)$ \\
\hline Number of metastatic lymph nodes & 0.285 & 0.224 \\
\hline$>1$ vs. $\leq 1$ & $3.42(0.31-37.85)$ & $2.68(0.52-13.88)$ \\
\hline Histological tumor grade & 0.747 & 0.537 \\
\hline High vs. low/intermediate & $1.20(0.39-3.75)$ & $1.30(0.56-2.99)$ \\
\hline Extranodal extension & 0.228 & 0.581 \\
\hline yes vs. no & $0.03(0.00-656.48)$ & $0.55(0.06-4.78)$ \\
\hline Perineural Spread & 0.222 & 0.403 \\
\hline yes vs. no & $0.27(0.03-2.60)$ & $0.41(0.05-3.51)$ \\
\hline Lymphovascular invasion & 0.163 & 0.587 \\
\hline yes vs. no & $4.72(0.43-52.22)$ & $1.64(0.27-9.82)$ \\
\hline Vascular invasion & 0.380 & 0.680 \\
\hline yes vs. no & $2.80(0.25-31.05)$ & $1.58(0.18-14.23)$ \\
\hline Bone invasion & 0.222 & 0.603 \\
\hline yes vs. no & $3.72(0.39-36.03)$ & $1.75(0.21-14.60)$ \\
\hline \multicolumn{3}{|l|}{ Treatment-related } \\
\hline Resection margin & 0.119 & 0.179 \\
\hline R1/2 vs. R0 & $5.04(0.52-48.53)$ & $2.81(0.62-12.72)$ \\
\hline Resection margin & 0.002 & 0.031 \\
\hline R2 vs R0/1 & $11.26(1.58-80.45)$ & $5.15(0.98-26.93)$ \\
\hline Second primary tumor resection & 0.293 & 0.543 \\
\hline yes vs. no & $0.034(0.00-910.95)$ & $0.52(0.06-4.37)$ \\
\hline Neck Dissection & 0.598 & 0.852 \\
\hline yes vs. no & $0.55(0.06-5.28)$ & $1.22(0.15-10.18)$ \\
\hline
\end{tabular}


Table 3 Patient-, tumor-and treatment-related factors compared to local and locoregional recurrences (Continued)

\begin{tabular}{lll}
\hline Univariate & & $\mathbf{0 . 7 0 8}$ \\
\hline Number of dissected nodes & $\mathbf{0 . 6 7 5}$ & $1.50(0.18-12.88)$ \\
$\geq 10$ vs. $<10$ & $0.60(0.05-6.64)$ & $\mathbf{0 . 2 4 6}$ \\
Lymph node density (\%) & $\mathbf{0 . 1 1 0}$ & $2.71(0.48-15.42)$ \\
$>4$ vs. $\leq 4$ & $56.27(0.01-637,456.03)$ & $\mathbf{0 . 6 9 8}$ \\
Radiation dose & $\mathbf{0 . 3 3 3}$ & $0.66(0.08-5.50)$ \\
$\quad$ 64Gy vs. $<64 G y$ & $0.34(0.04-3.31)$ & $\mathbf{0 . 1 0 8}$ \\
Planning target Volume & $\mathbf{0 . 3 1 8}$ & $34.53(0.03-47,010.85)$ \\
primary tumor region \& & $28.57(0.00-1,127,372.02)$ & \\
regional lymph drainage vs. & & $\mathbf{0 . 2 2 6}$ \\
primary tumor region & & $0.290(0.03-2.45)$ \\
Radiation technique & 0.099 & \\
IMRT vs. 3D & $0.02(0.00-82.02)$ & \\
\hline
\end{tabular}

\section{Abbreviations}

ACC: Adenoidcystic carcinoma; CT: Computer tomography; DFS: Disease-free survival; DM: Distant metastases; IMRT: Intensity-modulated radiotherapy; LC: Local control; LET: Linear energy transfer; LRC: Locoregional control; OS: Overall survival; PFS: Progression-free survival; Pn1: Perineural spread; R0 resection: complete resection; R1 resection: microscopically positive resection margins; R2 resection: macroscopically positive resection margins; SGC: Salivary gland cancer

\section{Acknowledgments}

We thank the Tumor Centre at the Friedrich-Alexander University ErlangenNürnberg, Erlangen, Germany for assistance with data acquisition

\section{Funding}

Not applicable.

\section{Availability of data and materials}

The datasets used and/or analysed during the current study are available from the corresponding author on reasonable request.

\section{Authors' contributions}

MaHa performed the analysis of the data and drafted the manuscript. CS, SS, $\mathrm{SL}, \mathrm{MaHe}, \mathrm{FB}, \mathrm{HI}, \mathrm{AA}$ and FR participated in drafting and revising the manuscript. All authors read and approved the final manuscript.

\section{Ethics approval and consent to participate}

For this type of study ethics approval is not required.

Written informed consent was obtained 'front door' from all patients allowing collection of their clinical data.

\section{Consent for publication}

Not applicable.

\section{Competing interests}

The authors declare that they have no competing interests.

\section{Publisher's Note}

Springer Nature remains neutral with regard to jurisdictional claims in published maps and institutional affiliations.

\section{Author details}

'Department of Radiation Oncology, University Hospital,

Friedrich-Alexander-Universität Erlangen-Nürnberg (FAU), D-91054 Erlangen, Germany. ${ }^{2}$ Department of Otorhinolaryngology, University Hospital,

Friedrich-Alexander-Universität Erlangen-Nürnberg (FAU), Erlangen, Germany.
${ }^{3}$ Institute of Pathology, University Hospital of Erlangen,

Friedrich-Alexander-Universität Erlangen-Nürnberg (FAU), Erlangen, Germany. ${ }^{4}$ Department of Otorhinolaryngology, University Hospital of Mannheim, Mannheim, Germany.

Received: 23 January 2019 Accepted: 22 March 2019 Published online: 23 April 2019

\section{References}

1. Spitz MR, Batsakis JG. Major salivary gland carcinoma. Descriptive epidemiology and survival of 498 patients. Arch Otolaryngol. 1984;110:45-9.

2. Terhaard $\mathrm{CH}$, Lubsen $\mathrm{H}$, Rasch $\mathrm{CR}$, et al. The role of radiotherapy in the treatment of malignant salivary gland tumors. Int J Radiat Oncol Biol Phys. 2005:61:103-11.

3. Garden AS, Weber RS, Morrison WH, Ang KK, Peters LJ. The influence of positive margins and nerve invasion in adenoid cystic carcinoma of the head and neck treated with surgery and radiation. Int J Radiat Oncol Biol Phys. 1995;32:619-26.

4. Chen AM, Bucci MK, Weinberg V, et al. Adenoid cystic carcinoma of the head and neck treated by surgery with or without postoperative radiation therapy: prognostic features of recurrence. Int J Radiat Oncol Biol Phys. 2006;66:152-9.

5. Schulz-Ertner D, Nikoghosyan A, Didinger B, et al. Therapy strategies for locally advanced adenoid cystic carcinomas using modern radiation therapy techniques. Cancer. 2005:104:338-44.

6. Jensen AD, Poulakis M, Nikoghosyan AV, et al. High-LET radiotherapy for adenoid cystic carcinoma of the head and neck: 15 years' experience with raster-scanned carbon ion therapy. Radiotherapy and oncology : journal of the European Society for Therapeutic Radiology and Oncology. 2016;118:272-80.

7. Pommier P, Liebsch NJ, Deschler DG, et al. Proton beam radiation therapy for skull base adenoid cystic carcinoma. Archives of otolaryngology--head \& neck surgery. 2006;132:1242-9.

8. Jensen AD, Nikoghosyan A, Windemuth-Kieselbach C, Debus J, Munter MW. Combined treatment of malignant salivary gland tumours with intensitymodulated radiation therapy (IMRT) and carbon ions: COSMIC. BMC Cancer. 2010;10:546.

9. Jensen AD, Nikoghosyan AV, Lossner K, Herfarth KK, Debus J, Munter MW. IMRT and carbon ion boost for malignant salivary gland tumors: interim analysis of the COSMIC trial. BMC Cancer. 2012;12:163.

10. Jensen $A D$, Nikoghosyan AV, Lossner $K$, et al. COSMIC: a regimen of intensity modulated radiation therapy plus dose-escalated, raster-scanned carbon ion boost for malignant salivary gland tumors: results of the prospective phase 2 trial. Int J Radiat Oncol Biol Phys. 2015;93:37-46.

11. Orlandi E, lacovelli NA, Bonora M, Cavallo A, Fossati P. Salivary gland. Photon beam and particle radiotherapy: present and future. Oral Oncol. 2016;60: $146-56$. 
12. Haderlein M, Scherl C, Semrau S, et al. Impact of postoperative radiotherapy and HER2/new overexpression in salivary duct carcinoma : a monocentric clinicopathologic analysis. Strahlentherapie und Onkologie : Organ der Deutschen Rontgengesellschaft [et al] 2017:193:961-970.

13. Al-Qahtani KH, Tunio MA, Bayoumi Y, Gurusamy VM, Bahamdain FA, Fatani H. Clinicopathological features and treatment outcomes of the rare, salivary duct carcinoma of parotid gland. Journal of otolaryngology - head \& neck surgery $=$ Le Journal d'oto-rhino-laryngologie et de chirurgie cervico-faciale. 2016;45:32.

14. Hong HR, Roh JL, Cho KJ, Choi SH, Nam SY, Kim SY. Prognostic value of lymph node density in high-grade salivary gland cancers. J Surg Oncol. 2015;111:784-9.

15. Ali S, Bryant R, Palmer FL, et al. Distant metastases in patients with carcinoma of the major salivary glands. Ann Surg Oncol. 2015;22:4014-9.

16. Gallo O, Franchi A, Bottai GV, Fini-Storchi I, Tesi G, Boddi V. Risk factors for distant metastases from carcinoma of the parotid gland. Cancer. 1997;80: 844-51.

17. Bradley PJ. Distant metastases from salivary glands cancer. ORL J Otorhinolaryngol Relat Spec. 2001;63:233-42.

18. Guerrero Urbano T, Clark CH, Hansen VN, et al. A phase I study of doseescalated chemoradiation with accelerated intensity modulated radiotherapy in locally advanced head and neck cancer. Radiotherapy and oncology : journal of the European Society for Therapeutic Radiology and Oncology. 2007;85:36-41

19. Gujral DM, Miah AB, Bodla $S$, et al. Final long-term results of a phase $1 / / I$ study of dose-escalated intensity-modulated radiotherapy for locally advanced laryngo-hypopharyngeal cancers. Oral Oncol. 2014;50:1089-97.

20. Karam SD, Rashid A, Snider JW, et al. IMRT with stereotactic body radiotherapy boost for high risk malignant salivary gland malignancies: a case series. Front Oncol. 2014;4:268.

21. Roberts PR, Jani AB, Packianathan S, Albert A, Bhandari R, Vijayakumar S. Upcoming imaging concepts and their impact on treatment planning and treatment response in radiation oncology. Radiat Oncol. 2018;13:146.

22. Mai Y, Kong F, Yang Y, Zhou L, Li Y, Song T. Voxel-based automatic multicriteria optimization for intensity modulated radiation therapy. Radiat Oncol. 2018;13:241

23. Miguel-Chumacero E, Currie G, Johnston A, Currie S. Effectiveness of multicriteria optimization-based trade-off exploration in combination with RapidPlan for head \& neck radiotherapy planning. Radiat Oncol. 2018;13:229.

24. Wagenblast S, Kampfer S, Borm KJ, Combs SE, Pigorsch SU, Duma MN. CTbased dose recalculations in head and neck cancer radiotherapy: comparison of daily dose recalculations to less time-consuming approaches Strahlentherapie und Onkologie : Organ der Deutschen Rontgengesellschaft [et al] 2018.

25. Sprave $T$, Verma $V$, Forster $R$, et al. Radiation-induced acute toxicities after image-guided intensity-modulated radiotherapy versus three-dimensional conformal radiotherapy for patients with spinal metastases (IRON-1 trial) : first results of a randomized controlled trial. Strahlentherapie und Onkologie: Organ der Deutschen Rontgengesellschaft [et al] 2018;194:911920.

26. Ernst-Stecken A, Lambrecht U, Mueller R, Ganslandt O, Sauer R, Grabenbauer G. Dose escalation in large anterior skull-base tumors by means of IMRT. First experience with the Novalis system. Strahlentherapie und Onkologie: Organ der Deutschen Rontgengesellschaft [et al] 2006;182:183-189.

27. Sahgal A, Chan MW, Atenafu EG, et al. Image-guided, intensity-modulated radiation therapy (IG-IMRT) for skull base chordoma and chondrosarcoma: preliminary outcomes. Neuro-oncology. 2015;17:889-94.

28. Haderlein M, Scherl C, Semrau S, et al. High-grade histology as predictor of early distant metastases and decreased disease-free survival in salivary gland cancer irrespective of tumor subtype. Head Neck. 2016;38(Suppl 1):E2041-8.

29. Laramore GE, Krall JM, Griffin TW, et al. Neutron versus photon irradiation for unresectable salivary gland tumors: final report of an RTOG-MRC randomized clinical trial. Radiation therapy oncology group. Medical Research Council International journal of radiation oncology, biology, physics. 1993;27:235-40.

\section{Ready to submit your research? Choose BMC and benefit from:}

- fast, convenient online submission

- thorough peer review by experienced researchers in your field

- rapid publication on acceptance

- support for research data, including large and complex data types

- gold Open Access which fosters wider collaboration and increased citations

- maximum visibility for your research: over $100 \mathrm{M}$ website views per year

At BMC, research is always in progress.

Learn more biomedcentral.com/submissions 